\title{
Who is "The Child"? Best Interests and Individuality of Children in Discretionary Decision-Making
}

\author{
Jenny Krutzinna | ORCID: oooo-0002-7949-5020 \\ Senior Research Fellow, Centre for Research on Discretion and Paternalism, \\ University of Bergen, Department of Administration \& Organization Theory, \\ Bergen, Norway \\ jenny.krutzinna@uib.no
}

\begin{abstract}
While the substantiation of "best interests" has received much attention, the question of how "the child" is conceptualised to ensure any action taken or decision made is in the particular child's best interests has been largely neglected. In this paper, I argue that the lack of robust understanding of who "the child" is, means that we continue to make many generalisations and category-based assumptions in determining the child's best interests. In addressing the challenge of doing right by the individual child, I propose a three-step approach based on a theoretical model of the child that avoids presumptions about child-typical needs and insists on an assessment of the child's individual characteristics, needs, qualities and circumstances, making it the only conceptualisation fully meeting the child centrism criterion required by children's rights as determined by the United Nations Convention on the Rights of the Child.
\end{abstract}

\section{Keywords}

best interests - CRC - welfare policy - discretion - child protection - decision making - well-being - children's rights - individual needs

\section{Introduction}

Today, much of the world operates under the premise that we have an individual and collective obligation to safeguard children. This moral obligation is widely enshrined in international (and national) law, with the result of having 
almost universal applicability through the United Nations Conventions on the Rights of the Child (CRC, 1989), which has been described as 'the lighthouse which guides discussions on how to address global justice for children' (Brando, 2019). All countries, except the USA, have committed to the protection of children's rights, and the consideration of state actions through a child-centric lens, through ratification of the CRC; furthermore, the CRC is not the only source of children's rights, and even in the USA, children are protected under various laws and the American constitution (Woodhouse, 2020).

A focal point of children's rights protection is the principle of the best interests of the child (РСВI). Initially, the best interests standard was defined by the goals of physical protection of children and their psychological well-being (Goldstein et al., 1973, 1979), but it has since become a full-fledged right under the CRC. Today, the PCBI is one of the four guiding principles in the protection of children and their rights more broadly. It derives from a core article of the CRC, Article 3, which provides:

In all actions concerning children, whether undertaken by public or private social welfare institutions, courts of law, administrative authorities or legislative bodies, the best interests of the child shall be a primary consideration (emphasis added).

As can be seen, the РСBI consists of three essential elements: "best interests", "a primary consideration" and "the child". While the former two have received significant attention in both legal and philosophical scholarly literature (e.g., Kelly, 2005), the final - and possibly most important - element has not been subject to comparable scrutiny. This may suggest that the meaning and definition of "the child" for the purposes of the PСBI are unambiguous, or at least sufficiently clear, to ensure the proper application of the РСвІ in decision-making processes.

In this paper, I argue that this assumption of clarity is misguided, both in principle and in practice, and that, to the contrary, we lack a robust understanding of who the child is when talking about "the child". The consequence is that despite a bona fide belief that we are assessing a child as a unique individual, with individual needs, traits and preferences, we continue to make many generalisations and category-based assumptions in determining the child's best interests. Despite increasing focus on respect for the individuality of the child in practice (e.g., Race and O'Keefe, 2017), research indicates that decisions often stop at generalised needs assessments (Križ et al, forthcoming), and as formulated by a family court judge: 'the leap from the generalised standard of 
the child's needs to the individual, that is a challenge' (interview K1, October 2020 ). In response to this creeping unawareness, I propose a method of evaluation that really does focus on the child as an individual. This method consists of three steps and is based on a conceptualisation of the individual child via a model of "the child" that provides a child-centric perspective suitable to guide decision-making within a wide range of contexts, including healthcare and child protection, by public agents. This emphasis on decisions - or, using the language of Article 3, actions - is crucial, as children are not only vulnerable due to their being humans (Albertson Fineman, 2008), but also because of their developing capacity to direct their own lives (Liebel, 2018). This notion of vulnerability contains a crucial element of responsibility, connoting special responsibilities to those whose interests are vulnerable to our actions and choices (Lindemann, 2019), which means that it is within our adult decision-making that we ought to reflect a child-centric position to take care of the needs and rights of the children whose lives are impacted by our actions.

This paper is organised in six parts. In part one, I introduce a new model, which encapsulates a conceptualisation of the individual child built on three spheres of an individual. In part two, the model's utility as a tool for discretionary decision-making is described, followed by a discussion of the significance of individuality for children's well-being in part three. In part four, two hypothetical case studies are drawn upon to illustrate child-centrism in decision-making practice, showing how applying the individual child model may improve discretionary decision-making. Responses to some potential objections to the model are addressed in part five. Finally, I conclude with a summary of how the model may promote children's rights and yield real benefits for children in best interests decision-making situations.

Conceptually, we often talk about "children" as if they were a homogeneous group, characterised simply by a phase of development known as "childhood" or by biological age (predominantly in law). From a philosophical perspective, the discussion of what a child is has been driven partly by a focus on an adult-child distinction (Schapiro, 1999), which provides invaluable insight into the moral position of children in comparison to adults but fails to pay sufficient attention to the nuances found within the expansive group of children. A distinction based on age, developmental status or in the form of "maturity" assessments, often utilised in law, is a simplistic approach to conceptualising an issue of great complexity, and may turn out to be too pragmatic, ignoring 
the individuality and uniqueness of each child. This 'necessarily simplistic legal logic' (Liebel, 2018: 600) of defining "child" by age, as the CRC does, serves to ascribe universal rights to children as a group; however, the disconnect between the child as an 'abstractive social construction' (ibid.) and the real life of the child has serious implications for the determination of the best interests of any given child. By neglecting important intra-group differences, including a diverse range of abilities, traits, interests, needs and preferences, we risk overlooking the individuality of children in favour of efficient and streamlined administrative decision-making. An imminent risk of such an approach is that children's well-being may be compromised by disregarding that no matter how alike two children may appear based on any particular metric, it is more likely than not that their needs are not identical.

The model of the individual child (MIC) aims to overcome this challenge by directing attention to all facets of children's needs and avoiding lacunae in the determination of a child's best interests. This is where the MIC differs from other models, such as the BIC-model (Kalverboer et al., 2017), which identifies 14 'environmental conditions for development' to determine the best interests of a child and is based the provisions of the CRC, as well as the CRC Committee's General Comment No. 14 (2013). The BIC bears similarity to assessment frameworks used in social work or child protection practice, such as the Common Assessment Framework (CAF, n.d.) or the risk factor framework by Ward et al. (2012; see also Krutzinna and Skivenes, 2020). In contrast, the MIC remains disinterested in generalising children's needs based on legal rights. Rather than formulating a list of concrete and universal needs of children, the model introduces a child-centric approach rooted in the fundamental understanding of every child as a unique individual, which has bearing on the determination of the individual child's best interests, as will be demonstrated with two case studies in part four below.

The MIC is based on three spheres, reflecting the different theoretical perspectives, which may be adopted when conceptualising a child (see Fig.1).

At least three such perspectives are conceivable: a) the universal child, b) the categorical child, and c) the individual child. While sphere a) characterises children based on their status as child and assumes sufficient similarity in terms of needs between all children, sphere $b$ ) groups children together based on relevant characteristics, which may vary depending on socio-cultural context. Examples include familiar vulnerability-based categories: very young age, female gender, ethnic minority background, poverty, and disability. In contrast, sphere c) takes into account these vulnerabilities in as far as they are relevant for the specific child but goes further in considering the child as she is with any additional characteristics, conceptualising the child in her entirety as a unique 


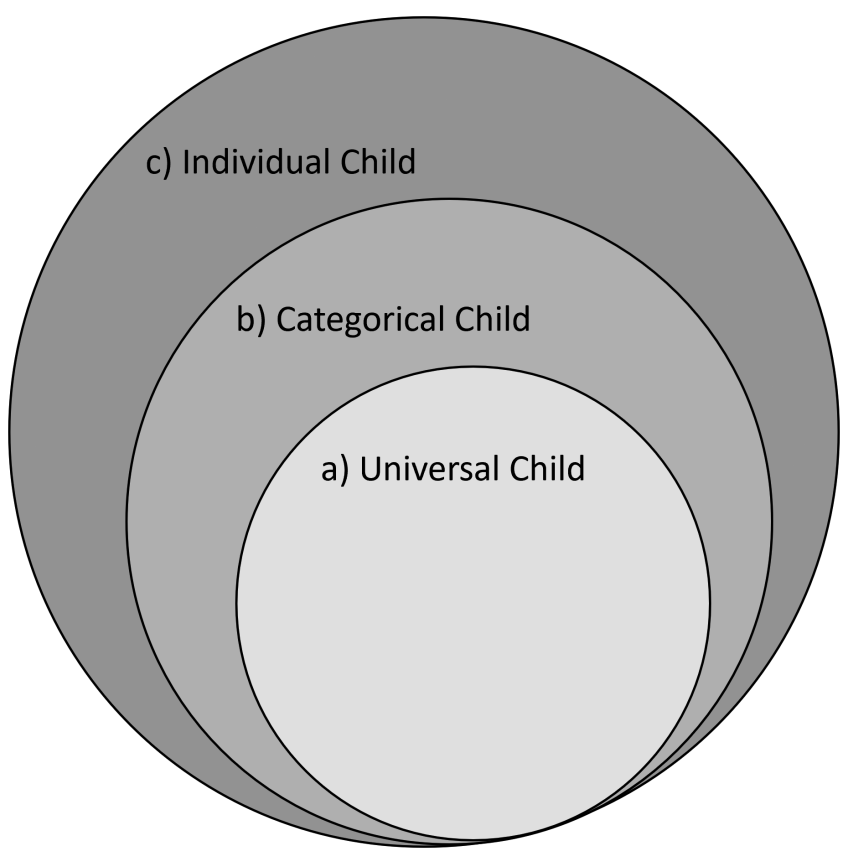

FIGURE 1 Three spheres of the individual child (at end of article and also delivered separately)

individual. The MIC combines these three perspectives, and thus conceptualises "the child" as an entity made up of three spheres:

\subsection{Sphere a): the Universal Child}

This first sphere contains the core characteristics of children as human beings (UNICEF n.d.), which is relatively straightforward, as there should be little controversy over the needs and requirements at this most elementary level. In this sphere, basic physiological needs are included, such as the need for food, water, shelter, and love and affection, which are shared by all members of our species in a more or less equal way (Maslow, 1943), as well as protection from physical and psychological harms or threats (e.g., maltreatment or abuse). In law, these needs are acknowledged and protected by human rights instruments, such as the European Convention on Human Rights (1950) or the Universal Declaration of Human Rights (1948), and most crucially for children, who have additional human rights needs due to their being children and not adults, via the UN Convention on the Rights of the Child. The CRC spells out general - or universal (cf. Brando, 2019) - rights of children, but often their implementation is then more specifically tailored to groups of children, e.g., indigenous children or children with disabilities, through other Conventions, which are covered under sphere $b$ ). 


\subsection{Sphere b): the Categorical Child}

The second sphere covers any group-specific characteristics of the child, i.e., those features a child shares with others belonging to a certain group. The aforementioned examples of vulnerability-based categories are but some of the possible groups that may be relevant in a best interests assessment. The respective existence and relevance of these categories is somewhat context-dependent and may also vary between jurisdictions because a specific characteristic may not be deemed a vulnerability in all situations. A theoretical example might be a status as an ethnic minority in one country but not in another, where the ethnicity is the predominant one.

Vulnerability-based categories are often targeted by specific legal and policy instruments, in recognition of a particular need for protection of interests and against discrimination. Prominent examples include the UN Convention on the Rights of Persons with Disabilities (CRPD, 2007) and the non-legally binding UN Declarations on the Rights of Persons Belonging to National or Ethnic, Religious and Linguistic Minorities (1992) and on the Rights of Indigenous Peoples (2007). A regional example is the African Charter on the Rights and Welfare of the Child (ACRWC), which recognises important socio-cultural and economic realities particular to Africa and responds to children's needs arising from living in specific social and cultural traditions (Organization of African Unity (OAU), 1990). These supra-national instruments are often implemented at the national level, through laws and regulations or policies. Typically, vulnerability-based categories are not child-specific (with the ACRWC being an exception), but their relevance to children is unequivocal: the combination of being a child and membership in one or more categories potentially enhances vulnerability and necessitates consideration of the child's position from an intersectionality perspective (see Barth and Olsen, 202O). The UN Committee on the Rights of the Child has attempted to address this challenge of intersectionality with some of its General Comments (see e.g. 20o6; 2009; 2014; 2017). The approach remains piecemeal, however, and does not reach to sphere c). As a child-specific instrument, the CRC also emphasises the need for special protection of certain categories of children, which are referred to as 'children in a vulnerable situation'. This will be addressed in more detail below.

\subsection{Sphere c): the Individual Child}

The third sphere comprises those characteristics that are features of the child as a unique individual. Here, additional vulnerabilities not captured by the typical categorisations are included, as well as any features of the child which are characteristics rather than vulnerabilities. This includes the child's preferences and interests. Approaches of determining what a child is do not shed light on 
who the child is, which is the aim of this third sphere, and which has enormous practical relevance on which actions should be taken or which decisions made regarding the specific child. In contrast to sphere b), we are here not concerned with determining what is in the best interests of a group of children, for instance, children belonging to an ethnic minority, but what is in the best interests of an individual child as a holistic and unique person. It is important to note that at this sphere c) level some balancing will be required if tensions arise between needs and preferences within sphere $b$ ) or c), or between spheres b) and c), as will be explored further in section four below. For instance, an ethnic minority child might have needs both to integrate into the predominant culture around her and to maintain her association with her own culture. This may lead to challenges in practice, where legal recognition of rights may only stretch so far in protecting all interests adequately. A possible way of tackling these challenges with a three-step approach will be presented below; but the crucial point is that some balancing between interests is necessarily required in practice and that this will be part of sphere $\mathrm{c}$ ) deliberations during the course of decision-making concerning a particular child, where the MIC can act as a useful tool.

\section{$3 \quad$ Informing Discretionary Decision-Making}

Before proceeding to explain the importance of conceptualising and treating children as unique individuals, an important caveat is in order. The MIC as a model of three spheres, like most models, has its limitations. Crucially, the two innermost spheres are to be understood as useful heuristics, i.e., they show how needs of children would have to be connected and how problems might arise if characteristics are overlooked. They do not, however, depict the full picture of what we find in the lived world, nor do they describe a path that ought to be followed strictly. The objective of the MIC is to have real benefit in practice, in decision-making concerning children, and not to be a perfect theory. To this effect, it is sphere c) where all the important deliberations are taking place, with spheres a) and b) merely providing input to the decision-making process.

The key advantage of the MIC is that it avoids presumptions about child-typical needs and insists on an assessment of the child's individual qualities, making it the only conceptualisation fully meeting the child centrism criterion required by children's rights. The CRC Committee (2013, para. 49) makes clear that all three aspects should feature in any best interests assessment and that 'determining what is in the best interests of the child should start with an assessment of the specific circumstances that make the child unique' (emphasis added). Simple categorisation in the form of exclusive reliance on sphere 
b) is explicitly dismissed as not meeting the criteria of individual assessment, because 'the best interests of a child in a specific situation of vulnerability will not be the same as those of all the children in the same vulnerable situation' (2013, para. 76). Thus, merely grouping children will not do. A situation of vulnerability is broadly defined as 'disability, belonging to a minority group, being a refugee or asylum seeker, victim of abuse, living in a street situation, etc.', leaving plenty of scope for other characteristics to be considered, and emphasising that 'each child is unique' (CRC Committee, 2013, paras. $75^{-76}$ ). In practical terms, the Committee (2013) calls for formal processes and strict procedural safeguards in the assessment and determination of the child's best interests, and imposes specific obligations on professionals, who must be adequately trained in relevant disciplines, including child psychology and child development, to enable them to make decisions based on the child's individual characteristics. This requirement is commendable, but reality is often bleaker, with workloads and budget constraints putting a limit to the competency development even the most invested professional can access (Interview $\mathrm{K} 2$, October 2020). This is reflected in the criticism of the CRC Committee's reports, which call on countries such as Germany and the United Kingdom to 'develop procedures and criteria to provide guidance to all relevant persons in authority for determining the best interests of the child in every area' (CRC Committee, 2014, para. 27; 2016, para. 27). It appears that the aspirations and professional ethos of those working with children are not always supported by the systems they operate in, resulting in tension within the discretionary space of professional decision-making (Molander et al., 2012).

Nevertheless, discretion has a critical role to play, as it allows for the necessary recognition of uniqueness of each situation, and an 'opportunity to be flexible, experimental, and sensitive to the particular' (Handler, 1986: 301), which is particularly important in the present context of children, because 'what is best for any child or even children in general is often indeterminate and speculative, and requires a highly individualised choice between alternatives' (Mnookin and Szwed, 1983: 8). Whilst arbitrariness is to be avoided to preserve justice (Dworkin, 1967; Hawkins, 1992), removing discretion in decision-making processes would also eliminate the possibility to take into account individual differences that have not been systematically accounted for in a set of rules. Since it seems inconceivable to create an exhaustive list of relevant differences, advocating against any discretionary space would appear futile. Thus, discretion provides the necessary room to manoeuvre complex life situations within a legal and regulatory framework, while retaining loyalty to important principles, such as the PCBI. The great advantage of discretion is that it creates a space which professionals may fill with their knowledge about 
children in general and combine it with the facts about the specific child in each case. Knowledge plays a critical role here, as it is a precondition for good decision-making which honours the child's best interests and respects the child as a moral agent with individual rights and interests. Thus, the discretionary space is crucial for the inclusion of individual circumstances, as rigid rules would be difficult to apply in highly complex social contexts without unduly risking the infringement of children's rights. This situation, however, opens a "discretion conundrum", because the same flexibility granted to allow for individual factors to be adequately considered may risk decisions being (perceived as) arbitrary. It is within this discretionary space that the MIC may prove particularly useful, by harmonising how best interests are assessed for each individual child. While a conceptual model such as the MIC cannot help alleviate economic or administrative constraints, it may serve as a useful tool in best interests decision-making by explicitly shifting attention from "a child" to "the child" at the heart of a decision to be made. This corroborates the shift towards more child-focused governance and the rise of children's rights, which have led to some modest legal recognition of inter-child differences, for instance, by referring to individual maturity in the child's right to be heard in court proceedings (e.g., Art. $12 \mathrm{CRC}$ ) and calls for consideration of the child's position even where age or other circumstances prevent direct hearing (Križ et al., forthcoming). This is a welcomed cautious attempt towards giving "the child" some agency in decision-making processes; however, the law is limited in its powers to instruct those processes further, because it is neither within the law's ability nor its aim to provide rules covering all possible circumstances, and thus, the resulting 'juristic black hole' (van Krieken. 2005: 26) must be filled by those entrusted with child-concerning decisions. Here, the starting point and dominant guiding principle is the PCBI which, as a fundamental right, is relevant for the interpretation and implementation of all other rights. Yet, despite the importance afforded to this one principle for the protection of children and children's rights, we do not know how "the child" in the PCBI is conceptualised in practice, making it difficult to assess its protective effectiveness for children and their rights. As a starting point, it seems safe to argue that "the child" is conceptualised as a human being, with basic needs. From this, we may hypothesise that the PCBI will work best to protect those rights and interests shared by all children, such as meeting physiological needs of food, water and shelter (Maslow, 1943). This is the elementary level of sphere a), where needs are more easily identified due to the limited variation between children, hence termed "the universal child". The further we move away from those most basic needs, the less adequate protection can be offered by a default understanding of "the child" within the PCBI. Instead, a nuanced, individualised understanding of "the 
child" will be required to identify and protect the more individual needs of a child. Where a (theoretical) child becomes "the child", a protective abyss opens, with potentially very serious consequences for child well-being. Historically, the concept of the best interests of the child had as its purpose the protection and welfare of children (Liebel, 2018: 605); and even today where this exclusive focus on welfare is no longer deemed sufficient, demanding instead a greater emphasis on children's participation, the protection of children's well-being remains a key aim of the PCBI. The relevance of this will now be explored.

\section{Protection and Well-Being of the Individual Child}

Why is it so important to account for individuality in best interests decision-making? The simple answer is that it is necessary for safeguarding the well-being of individuals; however, well-being in itself is a complex concept, which has resulted in extensive literature on the normative issue of what is good for someone (Griffin, 1989; Kraut, 2009), centring on notions of wellbeing and flourishing. The challenge with well-being is that it is difficult to tease out what is a good for a specific person, and different approaches have only managed to provide partial answers to this question (Krutzinna, 2016). This compares to the discussions regarding "best interests" (Kelly, 2005). Regardless of one's preferred approach, well-being is not merely a question of wealth or pleasure, but of a person's ability to live their life in a way that to them is meaningful, a life that has value to the individual. Here, the recognition of human diversity is fundamental; it has deep consequences for our understanding of social good and of equality (Sen, 1979). A prominent example is the capabilities approach, which is based on the idea of diversity among human beings, with differences in needs between persons, meaning the utility of certain goods will vary from one person to another (Sen, 2001; Nussbaum, 2011). Consequently, the capabilities approach acknowledges a person's actual capability to make use of goods, services and opportunities available to them, and explains why recognising a person as a unique individual is crucial: a universalised conception of needs will treat unfairly those who differ from statistical averages, social or cultural norms, or otherwise.

In the context of children, although no child-specific theory of well-being currently exists (but see Bagattini and Macleod, 2015), a significant body of literature addresses the moral permissibility of actions taken with regard to children, based on the child's right to an open future (Feinberg, 1980), children's rights (Archard, 2015), or even bioethical principles (Beauchamp and Childress, 2001). All of these approaches view children as deserving of special 
consideration and protection of their nascent autonomy and self-determination but remain mostly on theoretical terrain with little help for practical issues (Krutzinna, 2017). Thus, while helpful for conceptualising a universal child, and to a lesser extent a categorical child, these approaches cannot substantiate "the individual child". Their normative perspective can explain why we ought to focus on the latter, but not what makes a particular child unique, or how to reach the level of considering individuality. Therefore, it is crucial to understand how "the individual child" can be conceptualised in practice, i.e., by including relevant traits, qualities or characteristics that serve to establish a child's uniqueness. Here, a holistic framework for defining the individual child for practical purposes based on solid theoretical foundations is needed. This is the purpose of the MIC, which provides a basis for an assessment of a child's individuality as part of $\mathrm{PCBI}$-based decision-making processes, which typically involve a great level of professional discretion (see above). Conceptualising the individual child via this model results in three distinct steps that decision-makers should follow to pay due regard to the child's individuality, her needs, characteristics and circumstances. It directs attention so that a particular child is not perceived and treated merely as $a$ child, as a representative unit of the group of children, rather than as an individual. This approach may be described as "guided discretion", whereby decision-makers best interests considerations are guided but not substantively determined. The objective of the MIC is thus to prevent the glancing over individual differences by emphasising the three spheres that make up the particular child. To illustrate how PCBI-based decision-making can be informed by the MIC, two hypothetical case studies will be presented in the next section. Although fictional, they contain factual elements and issues common in real-life cases.

\section{Applying the MIC in Best Interests Decision-Making}

Alex attends the local kindergarten. She is a smart kid, but the staff have noticed that she is almost always alone in the sand pitch outside or playing with a toy in a corner of the playroom. Alex's parents only moved to this country a year ago and although they are quickly learning the local language, they speak their native language at home and with Alex. After several weeks, Alex still does not join in with the other children when they sing or play together. In a meeting with the parents, the head of the kindergarten, Ms Smith, expresses her concern for Alex's social and linguistic development. 
As a starting point, we may assume that Ms Smith is an experienced professional who will have seen many different children flourish or struggle in kindergarten. Her decision to discuss the situation with Alex's parents thus seems justified and based on a genuine concern for Alex's long-term well-being. The challenge in this situation is to determine what is best for Alex, what is in her best interests, given who she is. On the facts of the case, we can see two underlying presumptions informing a decision. The first is that all children have a need for social contact and friendship, and they also have a legal right to play (Art. $31 \mathrm{CRC}$; see also Woodhouse, 2020). Second, in the case of children with a migrant background, there is a particular need to ensure social integration against the odds of potential language and cultural barriers, and to provide sufficient support during the period of settling into a new environment. Ms Smith's wish to do something about Alex's situation is thus addressing both a universal level-need (social connections) and a category level-need (migration-related integration). A possible action taken based on theory and experience may thus result in the following:

Ms Smith suggests to pair Alex with one of the other children, Lucy, to help her integrate into the group and make friends. Lucy is a lively girl, who talks a lot and would be able to assist Alex in picking up the language. Ms Smith tells Alex's parents that this approach has worked well in the past, that it will help ensure Alex becomes well integrated into her peer group and that she overcomes any language issues ahead of her starting school.

This appears to be a suitable solution to address the challenges of the specific child, Alex. The pragmatic approach would be to simply try it out and see if it works, provided Alex's parents agree, which given Ms Smith's professional qualifications and experience they would seem likely to do, as they have no reason to distrust her on this matter. But how can we be sure this is in Alex's best interests? What does she have to lose if the decision turns out to be the wrong one for her? For all we know at this stage, we might conclude that this is a robust and good approach, which covers some important basic CRC rights (e.g., right to education, right to development), as well as rights of children in a vulnerable position (e.g., migrant children).

At this stage, Ms Smith is navigating solidly within sphere b), both in terms of her knowledge about Alex and her assessment of Alex's needs. Without reaching into sphere $\mathrm{c}$ ), there is a risk a decision will be made that is not in Alex's best interests and her well-being might be endangered. If Ms Smith had knowledge of the MIC, she might notice her knowledge gap concerning Alex and could take further steps to move from sphere a) to c) to comprehend 
Alex as a unique individual and not merely a child. By considering her migrant background, Ms Smith has already partially moved from sphere a) to sphere b) but the approach is incomplete. First, she needs to consider if there are any other category-level aspects that are relevant. The CRC Committee (2013, para. 75) provides some good pointers on what these may be, by drawing attention to 'situations of vulnerability', which includes 'disability, belonging to a minority group, being a refugee or asylum seeker, victim of abuse or living in a street situation.' It is important to note that this list is non-exhaustive, meaning that other categories may be relevant for a particular child. While we lack information concerning Alex to conclude on all these categories (and any others), these examples reveal the complexity of a proper sphere b) assessment. This is further complicated when several situations of vulnerability coincide. Since there is no hierarchy of vulnerability situations, it is not sufficient merely to replace one category with another, because the combination and interaction of different factors matters. Here, intersectionality comes to play. To illustrate this point, we can take our case further:

In the meeting, Alex's parents tell Ms Smith that their child is not like most other children. She much prefers to play on her own, as she finds the noise and movements by other children distracting. They report that they have spoken to a professional about this, who explained that Alex's brain is easily overstimulated from processing everything around her and recommended to allow her to withdraw whenever she so wishes.

We have now learned that Alex is different to other children Ms Smith knows. Since the importance of learning the language and connecting socially with other children (universal level-needs) has not disappeared, we need to reflect carefully what we can do to ensure Alex's needs at all levels are met. Here, the temptation to find another, better fitting category is real. For example, Ms Smith may suggest Alex get a medical diagnosis that puts her on the autism spectrum (ICD-11, n.d.). The risk here is that one category (disability) is prioritised over another (migrant background), without knowledge about Alex's actual needs due to the interaction between her different traits (intersectionality). It is thus crucial not to uncritically change protocol in the case of a suspected new category-level need (e.g., disability-related), but to reach to the individual level, and identify what this particular child needs. Only then can we effectively safeguard Alex's well-being and respect her as a unique individual and are not reliant on needs-assumptions linked to established categories that may be ill-fitting. Especially where health and disability are concerned, labelling or categorising children can have serious consequences for the perception and 
self-perception of the child and there are often strong systemic incentives for identifying "abnormality" in a child, for instance access to additional support and services in case of a diagnosis, leading to over-medicalisation or "diagnostic creep" in childhood (Krutzinna, 2019). To ensure labels fit and interventions work for a particular child, a sphere c) assessment is unavoidable. This requires a three-step approach, described in the following.

\subsection{Categorise - Individualise - Balance}

To ensure that a thorough individual child assessment is carried out, the move from sphere $b$ ) to sphere c) follows three steps.

"Categorise" is the first step, which involves identification of the needs of "the categorical child". This is challenging, as it first requires establishing all relevant categories, before determining which needs are associated with each category. The CRC Committee has provided a list of categories which may be considered indicative of some of the most relevant considerations, such as disability, ethnic minority background, poverty, and having experienced abuse, amongst others (UN Committee on the Rights of the Child, 2013), and has issued General Comments on a number of these (see e.g. 2007; 2009; 2014; 2017). Ascertaining the specific needs linked to each of these categories requires in-depth knowledge of the particularities, characteristics and vulnerabilities of the group, but significant convergence of needs of the members of each group may be anticipated. If done properly, this level will already provide substantial protection of a child's needs and legal rights; however, it cannot be described as fully child-centric, as consideration of the actual child is still lacking. To do so, the next step may seem an obvious one.

"Individualise" involves, first and foremost, talking to the child directly to understand her views, preferences and concerns. This is enshrined in law as the child's right to be heard and to have her views taken into consideration in all matters concerning her (Art. $12 \mathrm{CRC}$ ). However, despite strong legal recognition, this right is not always respected in practice (McEwan-Strand and Skivenes, 2020), and in some cases may be impossible to implement (e.g., due to young age or impairment) (but see Križ et al., forthcoming). In our example, talking to Alex can give us some indication about her own perspective, for instance, whether she feels unhappy or isolated, or if she is in fact enjoying herself. Talking to the child may provide some useful clues as to whether an action may at all be required at this moment in time. It may, however, also be the case that talking to her does not give us a clear answer (e.g., "I don't know"), that her feedback is contradictory ("I like playing alone. I feel lonely.") or that she expresses an impossible wish ("I need a dog to play with"). Important here is that the purpose of talking and listening to the child is not delegating 
responsibility for the decision to her, something which might prevent her from talking openly to adults (Interview $\mathrm{K}_{3}$, November 2020). Not only would this impose an undue burden on the child, but it is also unlikely to result in a decision that is in the child's best interests. The lack of actionable insight from talking to the child does not excuse us from our obligation to gain further knowledge about the child as an individual, however. This also applies where talking to the child may not be an option. Here, we need to make a real effort to find out who the child is, and as the above case study shows, we cannot rely on policies to cover sphere c), the individual level. While policies may be a useful starting point, especially where they are evidence-based, and may tell us what to look out for, they will not provide us with sufficient information about the child as a holistic individual, with the complexities that come with real lives.

"Balancing" is thus the final step, in which "the individual child" is addressed. In this final and important step, the actual child will be revealed during the process which may involve adding, removing and amending needs, traits, qualities and characteristics; thus, this last step involves the balancing of all the needs of the unique child to determine the appropriate course of action and decision-making that is in the best interests of the child. The starting point is the knowledge gained from step one, in which all the categories of protection applicable to the child are identified and put on the table. From this, we might draw up a list of needs; however, these will not be in a hierarchical order until we combine it with our learnings from step two. The individualised knowledge obtained from talking to the child directly, or from getting to know her through more indirect means where necessary, will help resolve the potential tensions arising from category-based needs, and will prevent us from acting against the child's own wishes/preferences without only the strongest of justifications.

In our case study, Alex's need as a migrant to learn the language, and her need to manage social interactions to avoid overwhelming her, must be reconciled in any action taken by the adults around her. Our obligation towards Alex is to act in her "best interests", and this balancing phase is our opportunity to do so, but the stakes are high. In Alex's case, the proposed solution of appointing a peer "to be a friend" seems innocuous, as it is built on solid assumptions concerning universal level-needs (to have social contacts and friends to play with) and category-level needs (to integrate socially and learn the local language). Yet, even if this peer approach were based on solid child development research, rendering the kindergarten teachers' proposal reasonable, well-informed and justified, it may still be wrong for Alex. The implication of disregarding her individuality could be to medicalise her way of being by treating her as having a disability she may not have, to signal that she is not the way children are or should be (regarding her reduced need for 
social interaction) or to discomfort her by forcing her to be more social than she is comfortable with. Ms Smith's job is no doubt a difficult one, because in some cases she may have to abandon standard procedure and policies that are intended to assist a group of children (e.g., migrants) in favour of doing what is best for the individual child. Ensuring that children develop appropriate language and social skills is an important part of her professional role, but if Alex's need to avoid overstimulation and her preference for limited play with other children are not taken seriously, her well-being may be threatened. If an alternative action is taken, for instance, a way of practising the language not involving an over-active peer could be found, Alex might be happier without sacrificing her longer-term needs.

The crucial element of the balancing step is the avoidance of standardised approaches to individual needs where this would not benefit the particular child's well-being. There is no blanket approach that will fit all children in all circumstances, but the sphere c) balancing step necessitates a certain openness to difference and creativity in finding solutions for meeting a child's needs. This is important because there is a fundamental risk that adults note "conflicts" between the child's needs, and in their eagerness to resolve conflicting conclusions on what should be done, fail to acknowledge that their adultperspective might not reflect the individual child's perspective. Situations where it is genuinely impossible to reconcile different needs a child has will be rare; they would typically only arise where the child's own wishes prevent it, for instance, if Alex strongly resists playing with anyone at all. In this situation, it would seem hard to make an argument for anything other than respecting her choice, and maybe return to the issue at a later time. Beyond such an extreme situation, Alex's need to integrate socially and her preference for lone play could be addressed by devising a plan for joint activities with some of the quieter children rather than with Lucy, and explicitly encouraging her to withdraw whenever she wants. This is by no means a ground-breaking proposal, but as discussed above, decision-making too often relies on adult assumptions and policies based on categories of children, with limited space for individualfocused considerations.

Having explained the challenges inherent in these best interests decisions and presented my proposed three-step approach to addressing them, it is time to test this out in a different context. I will first present another short case study, before giving a simplified run-down of the three steps.

After a year of fighting, Kim's parents have announced their separation. Kim's mother has found a new partner and is about to move in with him, while Kim's father will stay in the current family home for the time being. 
The family must now decide on the living arrangements for Kim but reaching any kind of agreement seems a distant dream. A social worker is called in for help and tells them that if no agreement is reached, the court will order alternating residence on an equal basis. Kim's parents wish to avoid the involvement of lawyers and thus decide that Kim should live with each parent half the time. The social worker affirms the parents' belief that it would be best for Kim to have equal access to both parents, to continue in her familiar environment as well as to follow her mother in settling into a new one.

It is important to note here that the parents' agreement is not based on their own deliberations, but on their expectation that the court would in any case decide on this arrangement, which they base on the information provided by the social worker. Their consensus is "tainted" by this information, which may have been misleading, as will be explained below. Averting the risk of lengthy and exhausting court proceeding thus appears a good choice, considering that genuine parental consensus is unlikely. The underlying presumption in this case, and the basis for the alternating residence policy, is that all children have a need for and a right to their parents (universal level-need). But is this decision really in Kim's best interests? We apply the three steps to find out.

Categorise: We do not have a lot of information about Kim, but she might certainly be described as in a vulnerable situation due to parental separation. For these children, there is a particular need to ensure continued access to both parents against the odds of emotional and logistical obstacles, and to provide as much stability as possible during the unsettled period of separation (category level-need). Other categories, such as disability or experience of abuse, might also be relevant and care must be taken not to overlook these in favour of the most readily apparent category (parental separation).

Individualise: Kim should be given the opportunity to present her perspective. We may assume that she indicates loving both her parents equally and thus she does not want to choose between them. She longs for stability after a year of unrest and mentions how much her family home means to her. She expresses concern about being far away from her friends who she currently meets most days and does not know how she is going to manage having two homes from now on. In an alternative scenario, she might also indicate a preference to stay with her mother only on weekends and during holidays but admits that when the adults suggested that it would be best for her to share her time equally between her parents, she felt compelled to concur.

Balance: Having determined the relevant protective categories applicable to Kim, we have to consider our assumptions of needs resulting from this categorisation. For instance, the need for stability which a 50/50 arrangement would 
meet, because it avoids constant re-negotiations about where Kim is to stay, must be balanced against Kim's own perspective. In the first scenario, Kim has only indirectly expressed her reluctance to share her time equally, while in the alternative scenario, her preference is made clearer. However, we can easily see how this directness may be difficult for Kim, as it could upset her mother and cause more friction between her already estranged parents. Therefore, close attention needs to be paid also to the subtle messages a child may send, rather than expecting an explicit preference to be expressed. With appropriate sensitivity and training, it should be possible to tease out Kim's views. Since Kim's actual preference is out of reach, i.e., that her parents reunify, this balancing is important in establishing a priority of needs to be met in any decision taken. Kim's input will be crucial in resolving tensions between her different level needs, and in many cases, her need and right to be taken seriously and have her views respected, will tip the balance in favour of her preference.

Based on this assessment, it might no longer be taken for granted that an out-of-court agreement is the best option for Kim, because it effectively deprives her of the opportunity to have her best interests as a unique individual considered appropriately. The legal process plays an important role here: the above case draws on the practice of court-ordered alternating residence following parental separation in Sweden. Assuming that it is generally in the child's best interests to live with both parents, Swedish law makes concessions, inter alia, for cases with a history of domestic violence or where parents are unable to cooperate with each other (Blomqvist and Heimer, 2016). In practice, however, the decision-making happens 'in the shadow of the law': social services inform parents during mediation talks that the courts are unlikely to deviate from the norm of joint legal custody and alternating residence (Newnham, 2011: 255), leading parents to agree to arrangements without any best interests assessments based on the individual child having actually taken place. This shows that the effectiveness of legal protections is contingent on their translation into practice; thus, in order to discharge their moral obligation to protect children, states must ensure not only that relevant laws and policies are in place, but also that they are applied in an effective manner that respects and treats each child as a unique individual.

Following the three-steps of the MIC-based approach would ensure that the individual child is taken into consideration and would lead to a rejection of the default out-of-court decision-making in cases like Kim's. Instead, a formal process would be required, whereby care is taken to discover Kim's actual preferences and to work with her to find the arrangement that best meets her wish to remain in her existing social environment and her need to have access to both her parents, without adult views overshadowing her own perspective. 
Consequently, a legal process might be unavoidable as the only way to ensure that the best interests of the child are adequately determined and protected.

What these case studies reveal, is that policies, rules, and decisions may appear to be child-centric, because they aim to address important needs of children, but they stay firmly on universal- and category-level terrain and fail to be child-centric on the individual level. This demonstrates that consideration of the type of child does not equate consideration of the actual human being at the receiving end of the decision; that such approaches may in fact be insensitive of the needs of the child concerned. However, incorporating the MIC and the C-I-B steps into best interests decision-making allows the discovery of the individual child for the purposes of taking actions that are in the best interests of the specific child in a given situation. The objective is not to provide a comprehensive checklist of all possible risks to a child, but to promote an approach that avoids overlooking important aspects of the individual child for whom a decision is made, or an action is taken. The overarching aim is thus to protect the well-being of every child by treating each child as an individual moral being, with rights and interests, in line with the spirit and provisions of the CRC.

Before presenting my final concluding remarks, some obvious objections to the utility of the MIC will be addressed in the next section.

\section{Responding to Objections}

A first objection might be that Alex's case is overly complicated, and that she should simply be seen by a child psychologist who could identify her development needs. Ms Smith could then follow a different set of guidelines which are more appropriate for children like Alex.

The response to this is twofold and depends on the precise purpose of the involvement of the psychologist. First, if the referral is purely meant as a means to diagnose Alex, and thus to categorise her, then this is problematic. The primary purpose of the MIC is to be sensitive to the individual and her needs, preferences and characteristics. It is insufficient to use shortcuts such as medical diagnoses to identify needs, as these will not necessarily apply to the child concerned. A wider concern is also that such a focus on "normality" may have implications for the construction of normative notions of childhood and the child (O'Reilly et al., 202O; cf. Nelson, 2021) that could be harmful for children in general. In addition, as discussed above, the importance of sphere c) is that tensions between needs and preferences may be resolved by considering the child as a unique holistic individual. Although it is possible that needs 
identified at sphere b) are identical to those relevant at sphere c), we cannot know until we have undertaken comprehensive sphere c) deliberations. This is also what children, and every child individually, is entitled to under the CRC. On the other hand, if the child psychologist is engaged to discover Kim's own perspective, to provide a safe space where she can freely express her thoughts and feelings, and ultimately to avoid the unnecessary labelling of Kim as a certain type of human being, then this would coincide with the C-B-I approach by enabling a more individualised best interests determination.

Second, in Kim's case, it might be suggested that if she does not freely speak her mind about her own position, it will always be difficult to find a solution that suits her in the short-term and still protects her long-term well-being.

Here, the response is that this also applies to Kim's own preferences and her voiced opinion, which may be contradictory or conflict with her own longer-term best interests. This illustrates the important distinction between individual child-centrism and child participation as talking to/hearing a child (Križ et al., forthcoming). The latter are necessary but not sufficient aspects in child-centric decision-making (given the usual caveats of children unable to express their views or direct testimony being more harmful to the child), while the former ensures that the child is "seen" as the person she is, regardless of her de facto contribution to the final decision taken. In Kim's case, adopting a MIC-informed approach could avoid the polarisation during the meeting, where the social worker and parents have different views on who Kim is and what she needs. The three-steps C-I-B approach would have encouraged both parties to dig deeper to discover the child's actual position, not merely in terms of her expressed preferences but holistically. It might have resulted in greater awareness of the fact that her unique situation requires adjustments to the standard policy application. Similarly, in Alex's case, it would have revealed that she is just slightly different from many other children, without merely categorising her character and consequently taking inappropriate action.

Third, concern may be expressed regarding the "discretion conundrum" described above, where higher priority given to the individuality of a child is seen as giving too much discretionary power to individual decision-makers to make decisions that may be arbitrary, biased or based on misinterpretations of the child's best interests.

In response to this objection, we need to first remember that decisionmaking that takes into account a child's individuality is not possible without at least some discretion. Given the impossibility of creating an exhaustive set of rules that caters for each and every child within the diverse and heterogenous group of children, there is simply no alternative to at least some discretionary space. While the MIC-based approach might not be able to stop the wilfully 
arbitrary decision-maker, which only a strict rule-based approach would, it can limit the risks inherent in discretionary decision-making processes in two important ways. First, by making explicit the requirement to consider the individuality of the child against common assumptions about child-typical needs, the MIC-based approach shifts attention from "a child" to "the child" at the heart of a decision to be made. This serves to remind decision-makers that they must make an effort to discover the individual child in each case, that they cannot rely on their existing knowledge about children and assumptions concerning their needs.

Second, by guiding discretion via the C-B-I steps, the MIC-based approach provides a harmonised way of assessing best interests that is transparent and may be scrutinised by others, at least when combined with a requirement to explain and justify a decision, as is typically the case in decision-making by state agents, who have to document their decisions. This is especially important where children for whatever reason cannot participate in the proceedings because it provides a check on potential misrepresentations of their individual interests.

Finally, another objection might be that expecting full child centrism is overly ambitious and that while policy should aspire to be child-centric, reality will force us to settle for "good enough" child centrism.

My response to this is simply that, besides children's existing legal right to be treated as individuals under the CRC, too much is at stake to settle for a minimum. What is at risk here is our communal attitude towards children, which only very recently has started to shift towards perceiving children as moral agents and independent entities (Barth and Olsen, 2020; Berrick et al., in press; cf. O'Neill, 1988). Misplaced pragmatism could jeopardise the small achievements made in children's rights, participation and, most recently, child-centric policies and politics. Ultimately, children's well-being would be sacrificed. As the above case studies demonstrate, children cannot be collectively protected by brushing over a child's individuality. What might be generally right for children, can be wrong for Alex or Kim, but might be right for another child in the same situation, and this is what needs to be captured in child-centric policies, for example, by adopting a MIC-based approach that explicitly considers children's individuality.

\section{$7 \quad$ Concluding Remarks}

Child centrism matters. For the child, for the family, for society. Failing to see the individuality of children may have serious consequences for both the child 
and the family; and has serious implications for society at large. Given the current legislative framework, not much is required to move towards greater focus on the individual child. Decision-makers are already well-equipped for making truly child-centric decisions because their discretionary space provides them with the flexibility to take into account individual differences between children and to deviate from typical needs where a particular child differs in a relevant way. This allows to cater even for children with counter-intuitive needs, like Alex, who does not have the same social and physical needs as most children. This is precisely what the CRC demands in its concern for all children, collectively and individually.

The MIC could provide the necessary conceptual framework to ensure decision-makers go the whole way and that they explore the third sphere representing the child's individuality. Despite their assertions of always determining the best interests of the child on a case-by-case basis, research has shown significant convergence in the factors considered in the decision-making process (Banach, 1998). This gives cause for concern, as pragmatism and custom in decision-making are likely to run counter to the individual needs - and rights - of the children concerned. Incorporating the MIC and following the C-I-B steps in all areas of decision-making concerning children would hopefully initiate an attitudinal shift towards the realisation that extensive professional knowledge about children alone does not provide sufficient knowledge about a particular child. Of course, experience with many different children increases the likelihood of familiarity with a broader range of children, their needs, and characteristics, but this cannot replace individual child-centric thinking. Only a truly child-centric approach to decision-making, and full application of the MIC in all cases, can prevent serious misjudgements about what is in the best interests of the individual child concerned. In the hectic setting of professional life, it is often tempting to "recognise" children as types of children we may have come across before, to subconsciously categorise every child and to stop at the second sphere. Furthermore, the economic realities of budget constraints and increasing managerialism in the professions mean that not all children will get what they deserve based on their individual qualities and needs. However, our moral obligation towards children remains untouched by these practical constraints, and thus we must not merely pay lip service to the idea of "best interests" but do our best to understand the child as the individual she is. Thus, while the MIC approach cannot solve the difficult issue of knowing what is best given the complex contexts these decisions have to be made in, it forces us to re-focus our thinking on the child as the person most affected by our decisions and helps create the best possible basis for making 
a child-centric decision. After all, it should be the individual child who is the primary consideration.

\section{Funding}

This project has received funding from the European Research Council (ERC) under the European Union's Horizon 2020 research and innovation programme (grant agreement no. 724460). Disclaimer: Publications from the project reflect only the author's views and the funding agency is not responsible for any use that may be made of the information contained therein.

\section{Acknowledgments}

My utmost gratitude to my colleagues at the Centre for Research on Discretion and Paternalism and the Practical Philosophy Research Group at the University of Bergen for their helpful comments on earlier drafts of this paper. A special thank you goes to Claire Fenton-Glynn for reaching out and providing invaluable feedback on a previous version, and to the anonymous reviewers for their constructive comments. Any errors and omissions remain solely my own.

\section{References}

Albertson Fineman, M., "The Vulnerable Subject: Anchoring Equality in the Human Condition", Yale Journal of Law and Feminism 2008 (20), 1-23.

Archard, D., Children: Rights and Childhood. (London: Routledge, 2014).

Bagattini, A. and Macleod, C. (eds.), The Nature of Children's Well-Being: Theory and Practice (Heidelberg: Springer, 2015).

Banach, M., "The Best Interests of the Child: Decision-Making Factors", Families in Society: The Journal of Contemporary Social Services 1998 (79(3)), 331-340. Doi. org/10.1606/1044-3894.992.

Barth, R. P. and Olsen, A.N., "Are Children Oppressed? The Timely Importance of Answering this Question", Children and Youth Services Review 2020 (110) 104780. Doi. org/10.1016/j.childyouth.2020.104780.

Beauchamp, T.L. and Childress, J.F., Principles of Biomedical Ethics (Oxford: Oxford University Press, 2001).

Berrick, J.D., Gilbert, N. and Skivenes, M., International Handbook of Child Protection Systems (Oxford: Oxford University Press, in press). 
Blomqvist, P. and Heimer, M., "Equal Parenting when Families Break Apart: Alternating Residence and the Best Interests of the Child in Sweden", Social Policy \& Administration 2016 (50(7)), 787-804. Doi.org/10.1111/spol.12138.

Brando, N., "Universalism, Embeddedness and Domination: An Analysis of the Convention on the Rights of the Child", Journal of Global Ethics 2019 (15(3)), 270286. Doi.org/10.108o/17449626.2019.1695221.

Common Assessment Framework for Children and Young People (CAF): https:// greatermanchesterscb.proceduresonline.com/pdfs/caf_guidance_practitioners. pdf.

Dworkin, R., "The Model of Rules", The University of Chicago Law Review 1967 (35(1)), 14-46.

European Convention for the Protection of Human Rights and Fundamental Freedoms, as amended by Protocols Nos. 11 and 14, 34 (1950).

Feinberg, J., "The Child's Right to an Open Future”, in W. Aiken and H. LaFollette (eds.), Whose Child? Children's Rights, Parental Authority, and State Power (New Jersey: Littlefield, Adams and Co., 1980).

Goldstein, J., Freud, A. and Solnit, A.J., Beyond the Best Interests of the Child (New York: The Free Press, 1973).

Goldstein, J., Freud, A. and Solnit, A.J., Before the Best Interests of the Child (New York: The Free Press, 1979).

Griffin, J., Well-Being: Its Meaning, Measurement, and Moral Importance (new edition) (Oxford: Oxford University Press, 1989).

Handler, J.F., The Conditions of Discretion: Autonomy, Community, Bureaucracy (New York: Russell Sage Foundation, 1986).

Hawkins, K., The Uses of Discretion (Oxford: Clarendon Press, 1992).

ICD-11-Mortality and Morbidity Statistics (n.d.). Retrieved: 14 June 2021, from: https:// icd.who.int/browse11/l-m/en\#/http\%3a\%2f\%2fid.who.int\%2ficd\%2fentity\%2f 437 815624.

Kalverboer, M., Beltman, D., Van Os, C. and Zijlstra, E., "The Best Interests of the Child in Cases of Migration: Assessing and Determining the Best Interests of the Child in Migration Procedures", The International Journal of Children's Rights 2017 (25(1)), 114-139.

Kelly, J.B., "The Best Interests of the Child: A Concept in Search of Meaning”, Family Court Review 2005 (35(4)), 377-387. Doi.org/10.1111/j.174-1617.1997.tboo48o.x.

Kraut, R., What is Good and Why: The Ethics of Well-Being (Cambridge: Harvard University Press, 2009).

Krutzinna, J., "Can a Welfarist Approach be Used to Justify a Moral Duty to Cognitively Enhance Children?", Bioethics 2016 (30(7)), 528-535. Doi.org/10.1111/bioe.12244.

Krutzinna, J., “Beyond an Open Future”, Cambridge Quarterly of Healthcare Ethics 2017 (26(o2)), 313-325. Doi.org/10.1017/Sog63180116ooo89X. 
Krutzinna, J., "Shaping Children: The Pursuit of Normalcy in Pediatric Cognitive Neuroenhancement", in S.K. Nagel (ed.), Shaping Children: Ethical and Social Questions that Arise when Enhancing the Young (Cham: Springer International Publishing, 2019): https://doi.org/10.1007/978-3-030-10677-5_2.

Krutzinna, J. and Skivenes, M., "Judging Parental Competence: A Cross-Country Analysis of Judicial Decision Makers' Written Assessment of Mothers' Parenting Capacities in Newborn Removal Cases", Child \& Family Social Work 2020 (26(1), 50-6o. Doi.org/10.1111/cfs.12788.

Liebel, M., "Welfare or Agency? Children's Interests as Foundation of Children's Rights”, The International Journal of Children's Rights 2018 (26(4)), 597-625. Doi. org/10.1163/15718182-02604012.

Lindemann, H., "Why Families Matter", in M.A. Verkerk, H. Lindemann and J. McLaughlin (eds.), What About the Family? Practices of Responsibility in Care (Oxford: Oxford University Press, 2019).

Maslow, A.H., "A Theory of Human Motivation", Psychological Review 1943 (50(4)), 370396. Doi.org/10.1037/hoo54346.

McEwan-Strand, A. and Skivenes, M., "Children's Capacities and Role in Matters of Great Significance for Them”, International Journal of Children's Rights 2020 (28(3)), 632-665. Doi.org/10.1163/15718182-028030o6.

Mnookin, R.H. and Szwed, E., "The Best Interests Syndrome and the Allocation of Power in Child Care", in Providing Civil Justice for Children (London: Edward Arnold, 1983).

Molander, A., Grimen, H. and Eriksen, E.O., "Professional Discretion and Accountability in the Welfare State", Journal of Applied Philosophy 2012 (29(3)), 214-230. Doi.org/10.1111/j.1468-5930.2012.00564.x.

Nelson, R.H., "A Critique of the Neurodiversity View", Journal of Applied Philosophy, 2021 (38(2)), 335-347. Doi.org/10.1111/japp.12470.

Newnham, A., "Shared Residence: Lessons from Sweden", Child \& Family Law Quarterly $2011(23(2)), 251-267$.

Nussbaum, M.C., Creating Capabilities (Cambridge: Harvard University Press, 2011).

O’Neill, O., "Children's Rights and Children's Lives", Ethics 1988 (98(3)), 445-463.

O’Reilly, M., Muskett, T., Karim, K. and Lester, J.N., "Parents' Constructions of Normality and Pathology in Child Mental Health Assessments", Sociology of Health \& Illness 2020 (42(3)), 544-564. Doi.org/10.1111/1467-9566.13030.

Organization of African Unity (OAU), African Charter on the Rights and Welfare of the Child (1990) Vol. САВ/LEG/24.9/49.

Race, T. and O'Keefe, R., Child-Centred Practice: A Handbook for Social Work (London: Palgrave Macmillan Education, 2017).

Schapiro, T., "What is a Child?", Ethics, 1999 (109(4)), 715-738.

Sen, A., Equality of What?, The Tanner Lecture on Human Values, Stanford University (22 May 1979). 
Sen, A., Development as Freedom (Oxford University Press, 2001).

UN Committee on the Rights of the Child, Concluding observations on the combined third and fourth periodic reports of Germany, CRC/C/DEU/CO/3-4, 2014.

UN Committee on the Rights of the Child, Concluding observations on the fifth periodic report of the United Kingdom of Great Britain and Northern Ireland, CRC/C/GBR/ $\mathrm{CO} / 5,2016$.

UN Committee on the Rights of the Child, General Comment No. 9 (2006), The Rights of Children with Disabilities (CRC/C/GC/9).

UN Committee on the Rights of the Child, General Comment No. 11 (2009), Indigenous Children and Their Rights under the Convention (CRC/C/GC/11).

UN Committee on the Rights of the Child, General Comment No. 14 (2013), The right of the child to have his or her best interests taken as a primary consideration (Art. 3, para. 1) (CRC /C/GC/14).

UN Committee on the Rights of the Child, General Comment No. 18 (2014), The Rights of the Child on Harmful Practices (CRC/C/GC/18).

UN Committee on the Rights of the Child, General Comment No. 21 (2017), Children in Street Situations (CRC/C/GC/21).

UN Convention on the Rights of the Child, United Nations, 1989.

UN Convention on the Rights of Persons with Disabilities, A/REs/61/106, 2007.

UN Declaration on the Rights of Indigenous People, A/REs/61/295, 2007.

UN Declaration on the Rights of Persons Belonging to National or Ethnic, Religious and Linguistic Minorities, A/RES/47/135, 1992.

UN Universal Declaration of Human Rights, 1948.

UNICE F. n.d., Child Rights and Human Rights Explained: https://www.unicef.org/childrights-convention/children-human-rights-explained. Accessed 18 October 2021.

Van Krieken, R., “The 'Best Interests of the Child' and Parental Separation: On the 'Civilizing of Parents', The Modern Law Review 2005 (68(1)), 25-48.

Ward, H., Brown, R. and Westlake, D., Safeguarding Babies and very young Children from Abuse and Neglect (London: Jessica Kingsley Publishers, 2012).

Woodhouse, B.B., The Ecology of Childhood: How Our Changing World Threatens Children's Rights (New York: NYU Press, 2020). 